\title{
Requirements for development of cMOOC platforms from the professional's perspective
}

\author{
Virginia de S. Venega ${ }^{1,2}$, Rita Suzana Pitangueira Maciel ${ }^{1}$ \\ ${ }^{1}$ Departamento de Ciência da Computação (DCC) - Instituto de Computação (IC) - \\ Universidade Federal da Bahia (UFBA) - Salvador - BA - Brasil \\ ${ }^{2}$ Instituto Federal de Educação, Ciência e Tecnologia do Tocantins (IFTO) \\ Formoso do Araguaia - TO - Brasil \\ \{virginia.venega, rita.suzana\}@ufba.br
}

\begin{abstract}
MOOC with a Connectivist approach (cMOOC) are heavily dependent on peer collaboration for knowledge construction. Requirements for elicitation for these environments are not a trivial task and should take different perspectives. This paper describes a study carried out with informatics and education professionals to identify the software requirements to compose cMOOC platforms. In this context, a questionnaire was applied and, after analysis, returned 116 requirements divided into 11 categories, coded in correlation with the four dimensions of connectivism. In the future, it is expected with this research to compose a requirement catalogue to contribute to software development in the cMOOC domain.
\end{abstract}

\section{Introduction}

Since 2012, MOOC (Massive Open Online Courses) became popular and emerged as an alternative to traditional online learning environments bringing with it the proposal to offer courses to an undetermined number of participants (massive) and with no formal prerequisites (open) [Grainger 2013; Knox 2018]. MOOC courses can be classified between xMOOC (eXtended MOOC) and cMOOC (Connectivism-based MOOC or Connectivist MOOC). However, a significant popularization of xMOOC was observed since they are platforms close to traditional Virtual Learning Environments (VLE) models, focusing on self-instructional materials and intense video usage [Tori 2018; Fassbinder, Fassbinder and Barbosa 2016].

Although xMOOC platforms have gained space even with high evasion rates [Grainger 2013], cMOOC have not achieved the same popularity. According to Grainger (2013), as these courses require more excellent knowledge about the connectivist approach to be designed and performed, cMOOC have not achieved the same success compared to established xMOOC platforms such as Coursera and edX.

Unlike xMOOC environments, whose domain has been exhaustively explored, cMOOC platforms development is little investigated. Consequently, there is no consensus on what software requirements these platforms should fulfil [Grainger 2013; Bakki, Oubahssi and George 2019; Amado and Pedro 2020; Bakki and Oubahssi 2021]. Domain application studies allow building a clear and concise vision about target systems to be developed, and this kind of analysis also enables systematization and reuse of software components previously identified and developed [Lamsweerde 2009].

Several studies sought to identify MOOC requirements [Fassbinder, Fassbinder and Barbosa 2016; Rohloff et al. 2019; Goopio and Cheung 2021; Ashrafi et al. 2021]. 
However, these requirements do not consider connectivism' characteristics. Our research work differs from the others because it seeks to identify which requirements a MOOC platform must fulfill to provide resources to a connectivist approach, therefore a cMOOC. In a previous phase, from the students' perspective, we identified a total of 89 requirements for Diversity, Autonomy, Openness and Interactivity, dimensions of Connectivism, proposed by Downes (2012) [Venega, Garrido and Maciel 2019]. In this study, our goal was to identify the software requirements needed to implement a cMOOC from education professionals' perspectives (teachers, tutors, online course administrators).

This paper presents a survey that aims to identify software requirements necessary to implement a cMOOC from professionals' perspectives in the roles of education professionals. We hope that the requirements identified favor the offer of online courses with greater collaboration among peers and the construction of collective knowledge, as advocated in the original conception of MOOCs [Siemens 2004].

Thus, this paper is organized as follows: Section 2 presents the concepts that provide the basis for this work. Section 3 presents the methodological process followed for conducting the survey and data tabulation. Section 4 presents the results and analysis of the data obtained, and, finally, we present the final considerations and future work in Section 5 .

\section{MOOC and Connectivism}

According to De Sousa and Perry (2018), the integration of traditional teaching and online instruction stand out among the challenges for promoting learning in MOOCs. Despite these environments contribute to information and knowledge democratization, pedagogical aspects (essential to stimulate and improve the capacity of individuals) should not be neglected. They must be available in these environments since they are essential to achieve satisfactory results, that is, knowledge appropriation [Gonçalves and Gonçalves 2015].

In this sense, Connectivism emerged as a learning approach that took digital technologies into account and was based on the principle of distributed knowledge through networks connections, and learning process being the ability to move through these networks [Downes, 2012]. Proposed by George Siemens and Stephen Downes between 2004 and 2008, Connectivism was presented as a possible approach from the perspective of new technologies and its effects in our society, regarding living, communicating, and learning [Siemens 2004]. For Siemens (2004), learning can happen in several ways (e.g., communities of practice, personal networks, and work-related activities), not restricted to formal learning spaces.

To clarify the essence of Connectivism, Downes (2012) presented four aspects considered fundamental for learning under the connectivist's perspective: Diversity, Autonomy, Openness, and Interactivity. In the Diversity dimension, subjects must interact with different perspectives involving the most significant number of points of view; Autonomy refers to the knowledge construction based on the individual's interests and decisions and not on the imposition of third parties; Interactivity is knowledge production by interaction among participants; In Openness, individuals must be able to interact in the environment in based in your own preferences [Downes 2012]. The software requirements proposed for the connectivist approach to learning presented in this work were conceived based on the four dimensions proposed by Downes (2012), guiding the appropriate methodological procedures for their identification. 


\section{Research Methodology}

This research has an exploratory character with quantitative and qualitative aspects, especially concerning data analysis [Wohlin et al. 2012], therefore a mixed or multimethod approach. According to Creswell and Clark (2011), the multimethod approach are data collection and analysis procedures that combine qualitative and quantitative techniques in the same research design. In this study, we chose the survey data collection technique and followed the methodology proposed by Kitchenham and Pfleeger (2002a, 2002b) for planning, application, and data collection. In addition, the coding technique [Miles, Huberman and Saldaña 2014] and Grounded Theory (GT) were used as a method to collect, code, and analyze the qualitative data acquired in the research [Hoda, Noble and Marshall 2010].

Coding relies on words as a basic means for refining data and takes place in cycles, called First Cycle and Second Cycle. The process consists of deriving general themes (codes) from written data to categorize groups of data of similar nature and assist in the analysis phase [Miles, Huberman and Saldaña 2014]. To carry out the qualitative data analysis, GT technique was also used. Open coding is the first step of analysis from raw data; this phase may be accompanied by memoing - process of writing notes about the GT process. In Constant Comparison Method occurs the grouping of codes to produce higher levels of abstraction concepts which later will be called categories. A core category is one able to relate meaningfully and easily with other categories. Selective coding occurs only of the core category to categories that are closely related. The process coming to an end when the data collection and analysis leads to a point of diminishing results (theoretical saturation) [Hoda, Noble and Marshall, 2010].

Identifying the software requirements needed to design cMOOC platforms from the perspective of IT and education professionals was initiated by collecting data through an online survey. In Figure 1, we highlight the methodological steps followed in this research, which were based on the steps defined by Hoda, Noble and Marshall (2010) and then, we present the research questions, details of the target audience, questionnaire design, pilot test and the questionnaire distribution.

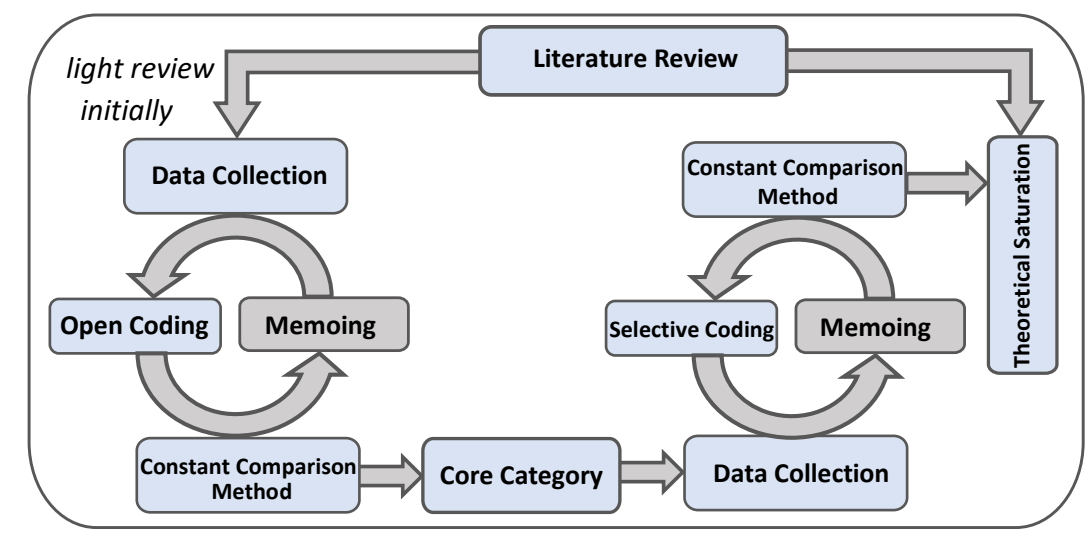

Figure 1 - Methodology (Adapted from Hoda, Noble and Marshall, 2010)

\subsection{Research Questions}

The following research questions were designed to guide the applied questionnaire:

RQ1. Are informatics in education professionals that use virtual learning environments familiar with MOOCs? This question investigates whether education 
professionals who are adept at technology-mediated education know and use MOOC of any nature, whether based on a connectivist approach or not.

RQ1.1. How do they evaluate their experience using these environments? This question investigates the perception of education professionals about the use of MOOC and VLE and seeks to investigate whether there is dissatisfaction or suggestions for improvement to these environments.

RQ2. Based on the connectivist approach, what resources or functionalities should these environments provide? With the presentation of the main concepts about cMOOC, this question investigates, according to the perception of education and technology professionals, the requirements to compose this kind of platform.

Based on these research questions, the questionnaire was designed aiming: (i) to know the profile of the interviewed professionals, their technical skills, and their level of knowledge about MOOC and (ii) to identify requirements for cMOOC supported by the four dimensions proposed by Downes.

\subsection{Identify and Characterize the Target Audience}

The questionnaire was addressed to education professionals with experience in Informatics. These professionals comprised teachers, managers, administrators of online learning environments, tutors, and content developers with direct contact with VLEs. As an online questionnaire, we decided to limit the public to these professionals' profile because they have the necessary background regarding concepts related to software engineering and software requirements. The following subsections present details of the planning and execution of the survey.

\subsection{Questionnaire Design}

To design the survey instrument, recommendations proposed by Kitchenham and Pfleeger (2002a, 2002b) were adopted. In line with the survey's guiding questions, the questionnaire was divided into three blocks of questions, the first being dedicated to knowing the profile of the respondent professionals, the second to assess the ownership degree over MOOC, and the third to identify and collect requirements suggestions.

The first section aimed to identify the respondents' training profile, use of digital technologies, technical skills, and perceptions related to using technologies for teaching purposes. The second block sought to identify the familiarity degree of the participants with the term MOOC and their experience in using online teaching platforms. The third block was divided into four sections, each dedicated to one of the guiding dimensions of the connectivist dynamics. For each section of block three, a brief description of the dimension in question was presented (Diversity, Autonomy, Openness, and Interactivity). Then, the user requirements defined by Garrido et al. (2019) for each dimension were presented. All sections in block three had two questions. The first one was a request for the respondent to transcribe their interpretation of user requirements to software requirements. The second was to propose complementary requirements according to the dimension in question. An explanatory video was available to assist participants in answering the third block questions, and each section had textual examples. The applied questionnaire (in Brazilian Portuguese) can be accessed through the link: bit.ly/39bG06O.

\subsection{Pilot Test and Questionnaire Distribution}

The pilot questionnaire was applied between April 19 and 25, 2020. Moreover, through feedback, the following changes were made: (i) correction of the introduction text; (ii) 
adequacy of some of the questions for a better understanding of the respondents; (iii) adequacy of the introductory explanatory text of the third block of questions and (iv) changing of a question to answer in the multiple-choice format.

After making the changes requested by the pilot questionnaire respondents, the survey was made available by email on several lists of Brazilian Computer Society, such as General lists, Software Engineering, and Informatics in Education; email lists of the Tocantins and Sergipe Federal Institutes, thematic groups of Informatics in Education and public and private universities in Salvador-BA. The questionnaire was available from May 1 to June 15, 2020, and as a population study, 31 subjects completed and returned the questionnaire. For the treatment and analysis of the results, the coding technique [Miles, Huberman and Saldaña 2014; Hoda, Noble and Marshall 2010] was used, and the results are presented in the following section.

\section{Survey Results}

The participants' profiles, regarding age, it was observed that $73 \%$ of respondents are between 32 and 59 years old and concerning the educational background, 77\% reported having training in the Informatics area (Computer Science, Systems Analysis, Degree in Computing and related), and $23 \%$ are trained in other areas of knowledge. As for professional practice, $70 \%$ work directly as professors while $30 \%$ work in the Education area, but not as teachers. They were also asked about the level of knowledge in SE. Most responses (97\%) indicated that respondents have some level of knowledge in SE, with $37 \%$ considering their level of knowledge as "High", 10\% as "Very high", and 30\% as "Moderate knowledge". Concerning professional experience in Requirements Engineering (RE) area, 43\% declared to have experience both in academy and industry, and $20 \%$ stated having experienced only in the academy.

The second block of questions served as a basis for answering RQ1 and RQ1.1, which sought to determine whether IT and Education professionals who use online learning environments were familiar with MOOC and their experience assessment in these domains. To answer these questions, it was asked about the use of VLE in their teaching practices. $90 \%$ of respondents reported using VLE in their practices, while only $10 \%$ did not.

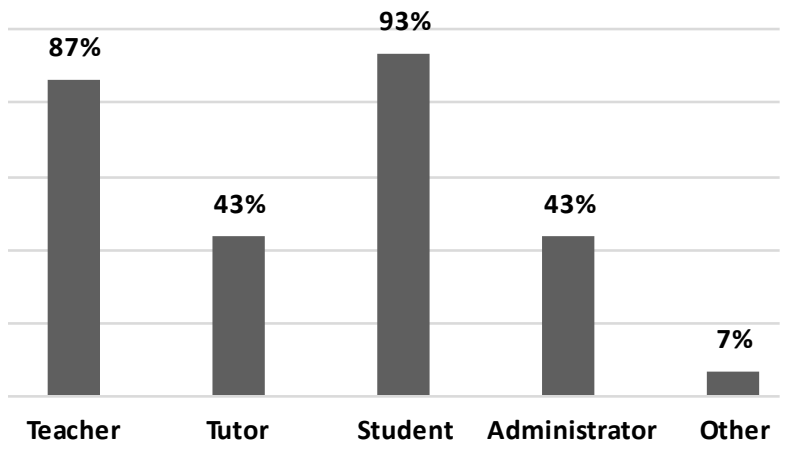

Figure 2(a) - Roles assumed in online learning environments.

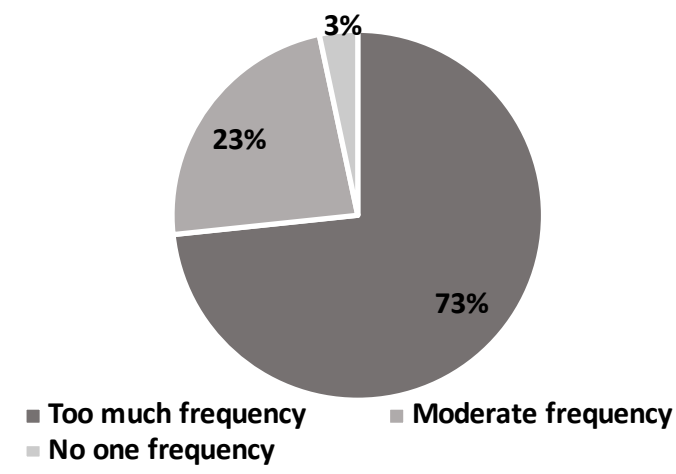

Figure 2(b) - Frequency in the use of virtual learning environments

Participants were also asked to inform the roles they have already taken on as VLE users and to report how often they use these environments (Figure 2(a)). Respondents were able to mark more than one answer and most of them had already assumed roles of student or teacher. As shown in Figure 2(b), we highlight that a 
considerable portion of respondents used VLE; only 3\% reported not using it. When asked explicitly about familiarity with MOOC, only 20\% indicated "Not familiar" (Figure 3(a)), demonstrating the adherence of the theme in the education professional's community. We highlight that Udemy (53\%), and Coursera (33\%) are the most indicated among the platforms concerning participation in these environments (see Figure 3(b)).

Asked how they evaluate their experience using MOOC environments, $80 \%$ of respondents reported that they believe that their experience can be improved, $17 \%$ reported not knowing how to answer and only 3\%, it appears, are satisfied with the available MOOC environments. Participants who considered that MOOC environments could be improved were asked about the improvements they would like to implement. Among the responses obtained, the following highlight: "evaluation methods improvement", "implementation of new strategies to improve collaboration in massive environments", "Artificial Intelligence technologies incorporation", and availability of resources for "measurement of study time from the students".

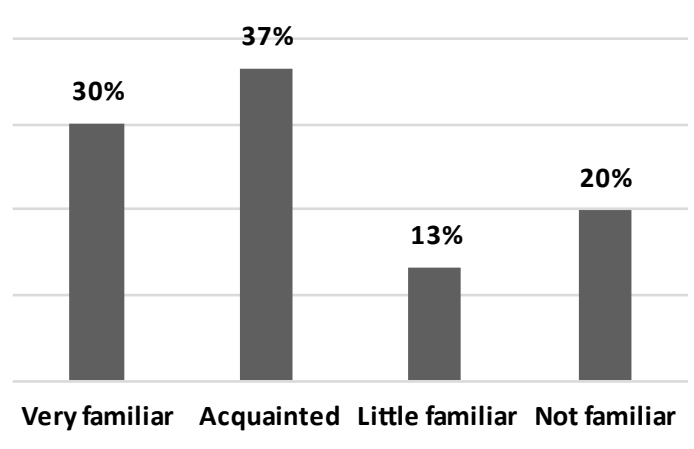

Figure 3(a) - Familiarity with MOOC.

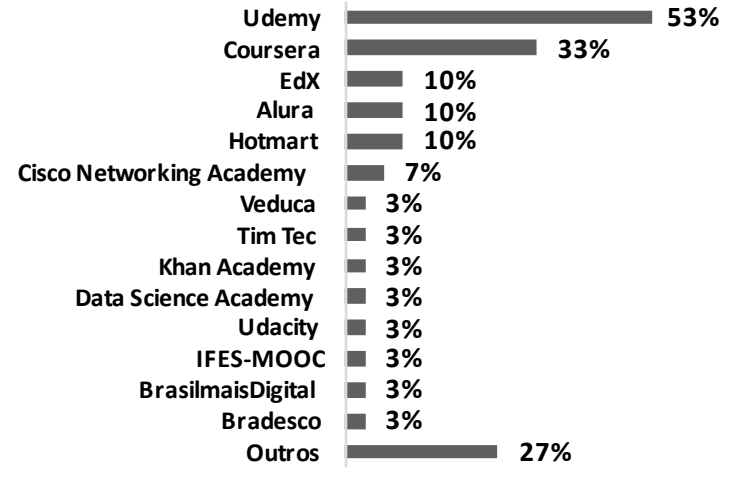

Figure 3(b) - MOOC performed by platforms.

The third block of the questionnaire aimed to answer the RQ2 of the research through eight questions in which users would enter requirements associated with the four dimensions of connectivism (Diversity, Autonomy, Interactivity and Openness) and additional requirements. For this, we use as a basis the user requirements proposed by Garrido et al. (2019) as a reference for transcription and expansion of the new requirements. The treatment and analysis of collected data were made by coding. Saldaña (2015) defines codes as words or phrases that deeply reflect a dataset's meaning. In this way, codes are attached to datasets and take the form of descriptive labels, used to categorize similar nature data. This method was used to analyze the collected data.

Initially, 94 requirements associated with the Diversity dimension, 56 requirements for the Autonomy dimension, 39 requirements for the Interactivity dimension, and 53 requirements for the Openness dimension were identified, totaling 242 requirements grouped into 16 categories in the first coding stage.

Table 1 - First and Second Cycle Coding Total Requirements

\begin{tabular}{c|cccc|c}
\hline & Diversity & Autonomy & Interactivity & Openness & $\begin{array}{c}\text { Total } \\
\text { Requirements }\end{array}$ \\
\hline $\begin{array}{c}\text { First Cycle } \\
\text { Coding }\end{array}$ & 94 & 56 & 39 & 53 & 242 \\
$\begin{array}{c}\text { Second Cycle } \\
\text { Coding }\end{array}$ & 43 & 29 & 25 & 19 & 116 \\
\hline
\end{tabular}


The second stage of coding aimed to refine the captured data. After the collected information treatment and analysis, 116 requirements distributed among the four dimensions were achieved, as shown in Table 1 . The number of categories was also reduced, reaching 11 . The following categories were identified after the second-round coding: Registration, Management, Language, Communication, Evaluation, Accessibility, Non-Functional Requirements (NFR), Recommendation, Gamification, Interoperability, and Collaboration.

Table 2 shows a sample of requirements acquired during the survey with professionals. This sample was selected because it has unusual characteristics (or functionalities) present in virtual learning environments. The complete list of requirements can be seen at: bit.ly/3kXFhOv.

The complete list of requirements (at the link above) presented a great concern of professionals in designing a plural cMOOC environment, as 43 of the requirements are related to diversity. Followed by autonomy with 29 requirements, indicating the consonance with the connectivist approach that prioritizes each student's voluntary and proactive collaborations in cMOOC.

Table 2 - Collected requirements grouped by Dimensions.

\begin{tabular}{l} 
Openness \\
\hline - The system should provide a webinar environment. \\
- The system should allow integration with social networks. \\
- The system should allow that users can define groups and members in collaborative activities. \\
- The system should allow artifacts produced by users in the environment to be evaluated by external \\
entities. \\
- The system should allow integration with video conferencing tools. \\
\hline \\
\hline - The system should allow the user to determine the proper pace of studies (non-linear learning). \\
- The system should provide an environment for user self-assessment. \\
- The system should allow the user to choose about conducting assessments for progression to \\
subsequent modules or not. \\
- The system should allow the recording of activity equivalence, so that a student can perform more \\
than one type of activity to achieve the same objective / competence. \\
- The system should allow the user to search and view the goals and objectives of other members of \\
the environment. \\
\hline \\
\hline - The system should allow incorporating of translation plugins for texts and videos (subtitles). \\
- The system should manage artifacts created by a user. \\
- The system should allow the sharing of messages between communities and users. \\
- The system should allow unified login (cross-platform). \\
- The system should allow users to evaluate the authors of shared content. \\
\hline
\end{tabular}

Regarding Table 2, the strong influence of web 2.0 is perceived, with indications of integration with social networks, the indication of authorship, permission to share productions on other platforms beyond the cMOOC environment. The next stage of the research will gather the data obtained in the two stages of the research to compose the requirements catalogue for the cMOOC domain. 


\subsection{Discussion}

While the first survey results highlighted the requirements for interaction between users and gamification (Venega, Garrido and Maciel 2019), the second emphasizes collaborative activities support. Many suggested requirements by education professionals reveal desire for mechanisms that allow activities and content production in groups, online and in a collaboratively way. Also highlighted requirements that suggest some resources inclusion such as videoconferences and webinars. The presence of requirements that require the possibility of recording equivalence of activities and artifacts management created by users, as illustrated in Table 2, demonstrate presence of the Autonomy and Diversity dimensions, cMOOC specificities pointed by Downes.

The analysis of the collected requirements, both surveys carried out with students and the one carried out with professionals, identified 11 (eleven) groups of requirements (codes). The table with the list of categories of requirements per survey can be seen at bit.ly/3ArpMDV. These categories allow us to note that eight requirement categories are common to both profiles of respondents. The students' results differ in the Social Networks, Navigation/Usability, and Moderation categories. In this context, we can infer that the student profile emphasizes the requirements related to social networks. This may indicate that this audience yearns for educational environments closer to the characteristics and tools related to their daily lives, which is strongly associated with the Openness and Interactivity dimensions. However, professionals differ from the students investigated in the Language, Non-Functional Requirements, and Management categories. In these categories, we observed, especially in NFR and Management, that control and environment requirements are the main concerns of professionals, devoting greater attention to the resources that can assist students' monitoring.

These findings open up research possibilities that have not yet been contemplated, such as developing a platform mainly focused on the connectivist approach. Thus, our contribution relies on providing requirements that can enrich knowledge about the cMOOC domain and assist development teams in this domain. The development of a cMOOC environment can be based on the requirements identified in our studies to optimize the process since the requirement's engineering phase has already been included in our results.

\subsection{Threats to the validity}

Threats associated with this study were identified during the planning and execution of the research. Thus, we present below the identified threats and the measures taken to mitigate their possible effects.

Construct Validity: This threat refers to the participant's understanding of the questions presented, especially in the third block questions. Refinements were carried out and descriptions were inserted in the body of the form, such as explanatory texts and videos. In addition, a pilot survey was carried out to certify the quality of the questionnaire.

Internal Validity: An internal limitation may be the audience selected to respond to the surveys prepared. Despite the significant amount of data collected, it is possible that this information is not sufficient to represent the entire population of users of MOOC environments. However, about $80 \%$ of respondents said they knew software 
requirements. As it was decided to preferably include professionals with some knowledge related to SE and RE, we believe this set can be representative.

External Validity: The set of 31 respondents who contributed to this study constituted the important framework that supported identifying requirements for cMOOC. Although the quantity of answers is not statistically relevant, 302 potential requirements were returned by these subjects, which leads us to infer that a significant volume of information was obtained to be analyzed and treated. Efforts to reduce the threat associated with the sample size consisted of massive dissemination of the questionnaire on mailing lists to elicit requirements.

Reliability: This risk is related to bias in interpreting the collected requirements, given that the coding was performed by only one person (first author of this work). To resolve this threat, at each coding cycle performed, the catalog was revised with the support of one or more evaluators. With this iterative process, we hope to have minimized the bias in judging a single point of view.

\section{Conclusions and Future Work}

This work presents the partial results of a research that has been conducted to identify the software requirements necessary for development of cMOOC systems. The study began capturing requirements for cMOOC from the users' perspective in the role of students. Initially, a survey was carried out with students of Software Engineering, which resulted in 89 requirements aligned with the connectivism dimensions.

In the stage presented in this paper, a second survey was applied with computer and education professionals to identify the requirements from the perspective of professionals in the roles of teachers, tutors, and administrators of courses made available in VLEs. The results generated a new set of requirements that will later be merged with the results collected from the student perspective to consolidate the requirements.

In cMOOC, knowledge is built and expanded through the relationship among its members. Our main intention with developing cMOOC environments relies on considering that this MOOC modality encourages collaboration among peers, different from xMOOC environments, which primarily provide content aimed at students' individual development. So, cMOOC favors the autonomy of the learner's community who will deal with topics produced by/in the community, approaching the context of Education 4.0 and promoting continuing education.

It is hoped with this research, to make available a catalog of requirements that can contribute to the minimization of problems arising from requirements elicitation activities for the cMOOC platforms development, as well as providing pedagogically adequate environments to objectives established by end-users, thus guiding, the stages of cMOOC software development in a systematic way. In future works, we intend to analyze the identified requirements with the support of a requirements engineer to refine the findings.

\section{References}

Amado, C., \& Pedro, A. (2020). "Elaboração de um framework para MOOC na Formação Contínua de Professores”. Revista Educação Em Questão, 58(58).

Ashrafi, S., Arasteh, H., Zinabadi, H., \& Abbasian, H. (2021). “Analyzing applied requirements for Massive Open Online Course (MOOC) in Payam Noor University 
from a Pedagogical perspective”. Quarterly Journal of Research and Planning in Higher Education, 1400(1), 51-87.

Bakki, A., Oubahssi, L., \& George, S. (2019). "Materializing Conception and Deployment Phases of a cMOOC Scenario”. In EMOOCs-WIP (pp. 20-26).

Bakki, A., \& Oubahssi, L. (2021). “A Moodle-centric Model and Authoring Tool for cMOOC-Type Courses”. In CSEDU (1) (pp. 545-556).

Creswell, J. W., \& Clark, V. L. P. (2017). Designing and conducting mixed methods research. Sage publications.

Downes, S. (2012). “Connectivism and Connective Knowledge: Essays on meaning and learning networks".

Fassbinder, A. G. O., Fassbinder, M., \& Barbosa, E. F. (2016). “Um Conjunto Preliminar de Requisitos Pedagógicos para Caracterização e Comparação de Plataformas de MOOCs”. In XXI Congresso Internacional de Tecnologia Educativa (TISE), Santiago, Chile.

Garrido, F., Fontan, N., Abreu, F., \& Maciel, R. S. P. (2019). "On the way for materializing cMOOC requirements: an experience dealing with plugins on Moodle Platform”. In Brazilian Symposium on Computers in Education (Simpósio Brasileiro de Informática na Educação-SBIE) (Vol. 30, No. 1, p. 566).

Gonçalves, V., \& Gonçalves, B. M. F. (2015). “Avaliação de plataformas para criação e distribuição de MOOC para a formação contínua de professores”. In International Conference on Innovation Documentation and Teaching Technologies. Universidad Politecnica de Valencia.

Goopio, J., \& Cheung, C. (2021). "The MOOC dropout phenomenon and retention strategies”. Journal of Teaching in Travel \& Tourism, 21(2), 177-197.

Grainger, B. (2013). “Introduction to MOOCs: avalanche, illusion or augmentation”. URL: http://iite. unesco. org/pics/publications/en/files/3214722. pdf.

Hoda, R., Noble, J., \& Marshall, S. (2010). "Using grounded theory to study the human aspects of software engineering”. In Human Aspects of Software Engineering (pp.12).

Kitchenham, B. A., \& Pfleeger, S. L. (2002). "Principles of survey research part 2: designing a survey”. ACM SIGSOFT Software Engineering Notes, 27(1), 18-20.

Kitchenham, B. A., \& Pfleeger, S. L. (2002). "Principles of survey research: part 3: constructing a survey instrument”. ACM SIGSOFT Software Engineering Notes, 27(2), 20-24.

Knox, J. (2018). "Beyond the "c" and the " $x$ ": Learning with algorithms in massive open online courses (MOOCs)”. International review of Education, 64(2), 161-178.

Miles, Matthew B., Huberman, A. M. and Saldaña, J. (2014). "Qualitative data analysis: A methods sourcebook. 3rd”.

Rohloff, T., Renz, J., Suarez, G. N., \& Meinel, C. (2019). “A ubiquitous learning analytics architecture for a service-oriented mooc platform”. In European MOOCs Stakeholders Summit (pp. 162-171). Springer, Cham. 
Saldaña, J. (2015). “The coding manual for qualitative researchers”. Sage.

Siemens, G. (2004). “Conectivismo: uma teoria de aprendizagem para a idade digital”. Trad. Bruno Leite.

De Souza, N. S., Perry, G. T. (2018). “Aprendizagem em moocs”. CIET: EnPED.

Tori, R. (2018). "Educação sem distância: as tecnologias interativas na redução de distâncias em ensino e aprendizagem” (Vol. 9). Artesanato Educacional LTDA.

van Lamsweerde, A. (2009). "Requirements engineering: From system goals to UML models to software”. Vol. 10. Chichester, UK: John Wiley \& Sons.

Venega, V., Garrido, F., \& Maciel, R. S. P. (2019). "Requisitos para adaptação de ambientes MOOC sob diferentes perspectivas educacionais”. In Brazilian Symposium on Computers in Education (Simpósio Brasileiro de Informática na Educação-SBIE) (Vol. 30, No. 1, p. 596).

Wohlin, C., Runeson, P., Höst, M., Ohlsson, M. C., Regnell, B., Wesslén, A. (2012). "Experimentation in software engineering”. Springer Science \& Business Media. 